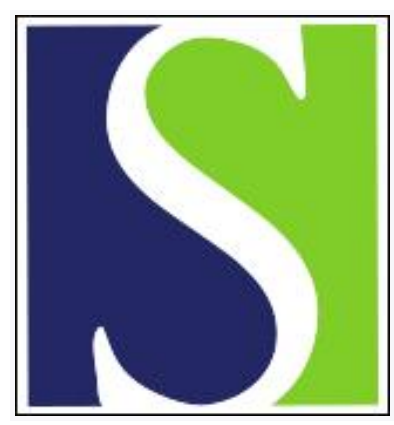

Scand J Work Environ Health 2000;26(6):470-475

https://doi.org/10.5271/sjweh.570

Issue date: Dec 2000

Nonmalignant mortality among workers in six Norwegian aluminum plants

by Romundstad P, Andersen A, Haldorsen T

Key terms: asthma; chronic obstructive lung disease; circulatory disease; fluoride; polycyclic aromatic hydrocarbon; potroom emission; primary aluminum smelter

This article in PubMed: www.ncbi.nlm.nih.gov/pubmed/11201393

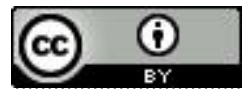




\title{
Nonmalignant mortality among workers in six Norwegian aluminum plants
}

\author{
by Pål Romundstad, MSc, ${ }^{1,2}$ Aage Andersen,${ }^{1}$ Tor Haldorsen, $M S c^{1}$
}

Romundstad P, Andersen A, Haldorsen T. Nonmalignant mortality among workers in six Norwegian aluminum plants. Scand J Work Environ Health 2000;26(6):470-475.

\begin{abstract}
Objectives This study investigated the associations between exposure to fluorides and polycyclic aromatic hydrocarbons $(\mathrm{PAH})$ and mortality from nonmalignant diseases among workers in the Norwegian primary aluminum industry.

Methods Mortality among 10857 men, employed for more than 3 years in 1 of 6 aluminum plants, was investigated from 1962 to 1996, giving 239246 person-years during follow-up. A job-exposure matrix covering all 6 plants was used to estimate the individual exposure to total fluorides and particulate PAH. The observed causespecific deaths were compared with expected figures calculated from national rates. Dose-response relations were investigated by internal comparisons using Poisson regression and by stratified analyses for standardized mortality ratio. Potential confounding by smoking was investigated in subanalyses restricted to 3 of the plants for which information on smoking habits was accessible.

Results Mortality from circulatory disease was slightly lower than expected [SMR 0.95, 95\% confidence interval (95\% CI) 0.9-1.0], while there was an increased mortality from asthma, emphysema, and chronic bronchitis combined, SMR 1.2 (95\% CI 1.0-1.5). Mortality from these diseases was associated with cumulative exposure to fluorides. The rate ratio in the internal analysis rose steadily to 2.5 (95\% CI 1.5-4.3) for the upper exposure category. No association was observed between cumulative fluoride exposure or PAH exposure and circulatory mortality.

Conclusions The study showed an association between exposure to potroom emissions measured by fluorides and mortality from asthma, emphysema, and chronic bronchitis combined.
\end{abstract}

Key terms asthma, circulatory disease, chronic obstructive lung disease, fluoride, polycyclic aromatic hydrocarbons, potroom emission, primary aluminum smelters

The primary aluminum industry is one of Norway's largest and most important industries, as the conditions for this type of industry have been favorable in Norway with its easy access to hydroelectric power. The aluminum workers have been exposed to a number of different agents, such as polycyclic aromatic hydrocarbons (PAH), fluoride salts and gases, sulfur dioxide, carbon monoxide, and alumina and carbonaceous particulates. Some of these agents may influence respiratory and circulatory mortality.

Most mortality studies from this industry have investigated cancer mortality, and only a few have focused on nonmalignant mortality. There are reports on increased morbidity and mortality from ischemic heart disease among potroom workers $(1,2)$ and on an association be- tween potroom work and mortality from cerebrovascular disease (2). Other studies have, however, found little evidence of an increased risk of circulatory diseases (36). Some studies also show conflicting results for mortality from obstructive lung disease, although most indicate an elevated risk (2-8). A Norwegian longitudinal morbidity study has, however, provided evidence of airway obstruction among potroom workers $(9,10)$. Asthma-like symptoms ("potroom asthma") have been among the most important health problems in this industry for several decades and have been reported in Norway since $1937(11,12)$.

The aim of our study was to investigate associations between exposure to fluorides (potroom emissions) and $\mathrm{PAH}$ in the aluminum industry and nonmalignant mor-

1 The Cancer Registry of Norway, Oslo, Norway.

2 Institute of Environmental Medicine, Norwegian University of Science and Technology, Trondheim, Norway.

Reprint requests to: Pål R Romundstad, The Cancer Registry of Norway, N-0310 Montebello, Oslo, Norway. [E-mail: pr@kreftregisteret.no] 
tality in a combined study of 6 Norwegian primary aluminum plants, focusing on mortality from chronic obstructive lung diseases and circulatory diseases.

\section{Subjects and methods}

Six aluminum smelters located in different parts of Norway were included in our study. A job-exposure matrix covering all 6 plants was constructed to estimate individual exposure to total particulate PAH and total fluorides as 8-hour time-weighted arithmetic averages. The fluoride measure also served as a surrogate for total dust, sulfur dioxide and carbon monoxide, as it was highly correlated with these exposures. Further descriptions of the exposure assessment, exposure levels, the process, and the smelters have been given elsewhere (13).

Because of the limited job information for those employed for less than 3 years, we included only those employed for more than 3 years. Information on each employee was obtained from company records giving name, date of birth, employment in departments, type of job, and dates for all job changes. Since 1964 all inhabitants in Norway have had a unique identification number, and these numbers were used for the linkage between data sources. Dates of death or emigration were found by linkage to the population register of Norway. Before 1964, the study population was linked to death register data by name and date of birth. We were able to identify 10857 men alive at the start of the follow-up. About 3\% (247) were not identified, and 292 men were identified, but found to be deceased prior to the start of the follow-up in 1962 .

Cumulative exposure was used as an indicator of individual dose and calculated for each person-year under observation as the product of the exposure intensity and duration summed for all jobs held. In the analyses "unexposed" person-time constituted 1 exposure category, and the remaining exposed person-years were allocated into 3 exposure categories based on the number of expected cases in each. Potential induction and latency periods were investigated by lagging exposure by 0,20 and 40 years $(14,15)$. A lag time of 20 years means that exposure during the last 20 years prior to each year of observation was disregarded.

\section{Smoking}

We had information on individual smoking habits from 3 of the plants. The workers were categorized as never, current, or former smokers, or as persons with unknown smoking status. A further description of the smoking data has been given elsewhere (13).

\section{Cause-specific mortality}

Because of the inclusion criterion of 3 years of employment, the follow-up of mortality started after 3 years of employment (net employment time) or from 1 January 1962 if the person in question had already been employed for 3 years before that date. Observation continued until 31 December 1996 or to the time of death or emigration. The cohort contributed 239246 person-years at risk to the study.

The grouping of causes of death was based on the 3digit code of the International Classification of Diseases (ICD), 9th revision. The observation period spanned the 7 th, 8 th, 9 th, and 10 th revision of the ICD codes. Since we used broad groups of deaths, the codes in the $7 \mathrm{th}, 8 \mathrm{th}$, and 10 th revision could be transformed to the 9 th revision (2). Cause-specific mortality was analyzed by calculation of the standardized mortality ratio (SMR). The SMR was calculated as the ratio between the observed and the expected number of deaths. The expected numbers were calculated from the biannual national mortality rate for men by 5 -year age groups. The $95 \%$ confidence intervals $(95 \% \mathrm{CI}$ ) were calculated on the assumption of a Poisson distribution for the observed numbers.

Although the calculation of SMR values offers some statistical advantages in precision, the comparison between different cumulative exposure categories using the SMR may be invalid (16). The use of internal analyses may offer a more valid assessment of potential dose-response associations and may also reduce potential biases from unknown confounders. Therefore, we performed analyses using Poisson regression for the investigation of internal dose-response relations and for the exploration of potential confounding from smoking. Age was included in the models using 6 age groups $(<55,55$ $59,60-64,65-69,70-79, \geq 80$ years), and the period of diagnosis was included using 3 calendar periods (1953-1970, 1971-1984, 1985-1996).

To investigate potential residual confounding due to the relatively wide age intervals, we performed sensitivity analyses using 8 and 10 age groups to evaluate possible effects on the effect estimates. Potential confounding by factors related to region of residence was investigated in supplementary internal analyses including indicator variables for plant.

Trend tests for the investigation of possible dose-response associations were performed by assigning scores from 1 to 4 for the 4 exposure categories or by applying the mean cumulative exposure to the exposure categories.

The calculations of the SMR values and the Poisson regression analyses were performed with the program package EPICURE (17).

\section{Results}

The total number of deaths among the aluminum workers was 3379 (table 1), which was close to the expected 
Table 1. Observed and expected numbers of deaths and the standardized mortality ratios (SMR) by cause of death among 10857 male aluminum smelter workers in the follow-up period from 1962 to 1996 . (95\% Cl = 95\% confidence interval)

\begin{tabular}{|c|c|c|c|c|}
\hline Cause of deatha & Observed & Expected & SMR & $95 \% \mathrm{Cl}$ \\
\hline $\begin{array}{l}\text { All causes }(1-999) \\
\text { Cancer }(140-209) \\
\text { Circulatory disease }(390-459)\end{array}$ & $\begin{array}{r}3379 \\
812 \\
1618\end{array}$ & $\begin{array}{r}3450.2 \\
791.4 \\
1699.0\end{array}$ & $\begin{array}{l}0.98 \\
1.03 \\
0.95\end{array}$ & $\begin{array}{l}0.95-1.01 \\
0.96-1.10 \\
0.91-1.00\end{array}$ \\
\hline $\begin{array}{l}\text { Ischemic heart disease }(410-414) \\
\text { Arteriosclerosis }(440,444,785) \\
\text { Cerebrovascular disease }(431-438) \\
\text { Hypertensive disease }(401-405)\end{array}$ & $\begin{array}{r}986 \\
34 \\
307 \\
46\end{array}$ & $\begin{array}{r}1072.7 \\
33.8 \\
327.7 \\
39.4\end{array}$ & $\begin{array}{l}0.92 \\
1.01 \\
0.94 \\
1.17\end{array}$ & $\begin{array}{l}0.86-0.98 \\
0.70-1.41 \\
0.84-1.05 \\
0.85-1.56\end{array}$ \\
\hline $\begin{array}{l}\text { Kidney disease }(580-87,791) \\
\text { Sudden death }(798) \\
\text { Digestive disease }(520-577) \\
\text { Respiratory disease }(460-519)\end{array}$ & $\begin{array}{r}24 \\
115 \\
73 \\
275\end{array}$ & $\begin{array}{r}18.6 \\
111.8 \\
63.2 \\
260.4\end{array}$ & $\begin{array}{l}1.29 \\
1.03 \\
1.15 \\
1.06\end{array}$ & $\begin{array}{l}0.83-1.92 \\
0.86-1.24 \\
0.91-1.45 \\
0.94-1.19\end{array}$ \\
\hline $\begin{array}{l}\text { Asthma, chronic bronchitis, emphysema }(490-93,496) \\
\text { Pneumoconiosis }(501-03,505)\end{array}$ & $\begin{array}{r}112 \\
7\end{array}$ & $\begin{array}{r}92.5 \\
3.5\end{array}$ & $\begin{array}{l}1.21 \\
2.01\end{array}$ & $\begin{array}{l}1.01-1.46 \\
0.81-4.14\end{array}$ \\
\hline External causes $(800-999)$ & 216 & 224.5 & 0.96 & $0.84-1.10$ \\
\hline
\end{tabular}

a Codes of the International Classification of Diseases, 9th revision, in parentheses.

Table 2. Poisson regression analysis of mortality (rate ratio) from chronic obstructive lung disease (asthma, chronic bronchitis and emphysema) by smoking status (subanalysis) and by cumulative exposure to total fluorides controlled for age and calendar period. $(95 \% \mathrm{Cl}=95 \%$ confidence interval)

\begin{tabular}{|c|c|c|c|c|c|c|c|c|}
\hline & \multicolumn{3}{|l|}{ Total cohort } & \multicolumn{5}{|c|}{ Subanalysis restricted to smokers and former smokers } \\
\hline & \multirow[b]{2}{*}{ Deaths $(N)$} & \multicolumn{2}{|c|}{ Smoking not included } & \multirow[b]{2}{*}{ Deaths (N) } & \multicolumn{2}{|c|}{ Smoking included } & \multicolumn{2}{|c|}{ Smoking not included } \\
\hline & & Rate ratio & $95 \% \mathrm{Cl}$ & & Rate ratio & $95 \% \mathrm{Cl}$ & Rate ratio & $95 \% \mathrm{Cl}$ \\
\hline \multicolumn{9}{|l|}{ Smoking status } \\
\hline Never & . & . & . & $-a$ & . & . & . & . \\
\hline Former & . & . & . & 2 & 1.0 & Reference & . & . \\
\hline Current & . & . & . & 27 & 6.6 & $1.6-28.0$ & . & . \\
\hline \multicolumn{9}{|l|}{ Fluoride exposure } \\
\hline $0 \mathrm{mg} / \mathrm{m}^{3} \cdot$ year & 20 & 1.0 & Reference & 5 & 1.0 & Reference & 1.0 & Reference \\
\hline $0.1-7.4 \mathrm{mg} / \mathrm{m}^{3} \cdot$ year & 24 & 1.3 & $0.7-2.4$ & 10 & 1.5 & $0.5-4.6$ & 1.7 & $0.6-5.1$ \\
\hline $7.5-19.9 \mathrm{mg} / \mathrm{m}^{3} \cdot$ year & 32 & 1.9 & $1.1--3.4$ & 8 & 1.6 & $0.5-5.1$ & 1.8 & $0.6-5.5$ \\
\hline$\geq 20 \mathrm{mg} / \mathrm{m}^{3} \cdot$ year & 36 & 2.5 & $1.5-4.3$ & 6 & 2.3 & $0.7-7.4$ & 2.3 & $0.7-7.5$ \\
\hline Evaluation of trend & & & P-value & & & P-value & & P-value \\
\hline Scores $1,2,3,4$ & & & $<0.001$ & & & 0.2 & & 0.2 \\
\hline Mean doseb & & & 0.001 & & & 0.4 & & 0.5 \\
\hline
\end{tabular}

a The subanalysis was restricted to smokers and former smokers since no deaths were observed among the never smokers.

- Arithmetic mean cumulative exposure in each exposure category was used.

figures calculated from national rates (SMR 0.98, 95\% CI 0.95-1.01). Mortality from circulatory disease was slightly lower than expected, (SMR 0.95, 95\% CI 0.91.0) based on 1618 deaths, while there was increased mortality from chronic obstructive lung disease (asthma, emphysema and chronic bronchitis combined) (SMR 1.2, $95 \%$ CI $1.0-1.5)$, based on 112 deaths. There were also more deaths from pneumoconiosis than expected (SMR $2.0,95 \%$ CI $0.8-4.1$ ), based on 7 observed deaths.

We found no association between cumulative fluoride exposure (potroom emissions) and cerebrovascular or ischemic heart disease mortality (results not shown). Neither did the data suggest any association between cumulative exposure to PAH and mortality from ischemic heart disease. The SMR of ischemic heart disease mortality varied only slightly from 0.9 to 1.0 in the different cumulative PAH exposure categories with confidence intervals between 0.8 and 1.1. Lagging of exposure by 20 or 40 years or the use of current exposure as an exposure indicator did not change the findings of no associations.

We also performed some additional analyses investigating potential associations between mortality from chronic kidney diseases and exposure to PAH and fluoride, but found no associations (results not shown).

We found, however, an association between cumulative exposure to fluorides and mortality from chronic obstructive lung disease. The SMR increased steadily from 0.7 (95\% CI $0.5-1.1)$ in the unexposed category to $1.8(95 \%$ CI $1.3-2.5)$ in the upper exposure category. Mortality from obstructive lung disease was further investigated in a Poisson regression analysis, which showed essentially the same results as the stratified SMR analyses (table 2). Since no death from chronic obstructive 
Table 3. Poisson regression analysis of mortality (rate ratio) from chronic obstructive lung disease (asthma, chronic bronchitis and emphysema) using both the underlying and the contributing causes of death by cumulative exposure to total fluorides and smoking status (subanalysis), when controlled for age and calendar period. (95\% $\mathrm{Cl}=95 \%$ confidence interval)

\begin{tabular}{|c|c|c|c|c|c|c|c|c|}
\hline & \multicolumn{3}{|l|}{ Total cohort } & \multicolumn{5}{|c|}{ Subanalysis restricted to those with known smoking habits } \\
\hline & \multicolumn{3}{|c|}{ Smoking not included } & \multirow[b]{2}{*}{ Deaths (N) } & \multicolumn{2}{|c|}{ Smoking included } & \multicolumn{2}{|c|}{ Smoking not included } \\
\hline & Deaths $(\mathrm{N})$ & Rate ratio & $95 \% \mathrm{Cl}$ & & Rate ratio & $95 \% \mathrm{Cl}$ & Rate ratio & $95 \% \mathrm{Cl}$ \\
\hline \multicolumn{9}{|l|}{ Smoking status } \\
\hline Never & & . & . & 3 & 1.0 & Reference & . & . \\
\hline Former & . & . & . & 11 & 2.4 & $0.7-8.6$ & & . \\
\hline Current & . & . & . & 50 & 5.4 & $1.7-17.4$ & r & . \\
\hline \multicolumn{9}{|l|}{ Fluoride exposure } \\
\hline $0 \mathrm{mg} / \mathrm{m}^{3} \cdot$ year & 40 & 1.0 & Reference & 11 & 1.0 & Reference & 1.0 & Reference \\
\hline $0.1-7.4 \mathrm{mg} / \mathrm{m}^{3} \cdot$ year & 53 & 1.4 & $0.9-2.2$ & 20 & 1.3 & $0.6-2.8$ & 1.4 & $0.7-3.0$ \\
\hline $7.5-19.9 \mathrm{mg} / \mathrm{m}^{3} \cdot$ year & 69 & 2.1 & $1.4-3.1$ & 19 & 1.8 & $0.8-3.8$ & 1.9 & $0.9-4.0$ \\
\hline$\geq 20 \mathrm{mg} / \mathrm{m}^{3} \cdot$ year & 65 & 2.3 & $1.5-3.4$ & 14 & 2.6 & $1.2-5.7$ & 2.8 & $1.3-6.2$ \\
\hline Evaluation of trend & & & P-value & & & P-value & & P-value \\
\hline Scores $1,2,3,4$ & & & $<0.001$ & & & 0.01 & & 0.007 \\
\hline Mean dose $e^{a}$ & & & $<0.001$ & & & 0.05 & & $0.03 a$ \\
\hline
\end{tabular}

${ }^{a}$ Arithmetic mean cumulative exposure in each exposure category was used.

lung disease was observed among the never smokers, the analysis investigating possible confounding by smoking was restricted to the groups of smokers and former smokers (table 2). In an additional internal Poisson regression analysis of chronic obstructive lung disease, we included the contributing causes of death, together with the underlying cause (table 3 ). This analysis showed results that were similar to those of the preceding analysis and suggested further that confounding from smoking was probably minor.

\section{Discussion}

\section{Main findings}

The study included employees from all the Norwegian aluminum plants that had been in operation for more than 30 years in 1996 . The main finding was the consistent positive association between exposure to potroom emissions, measured by fluoride exposure, and mortality from chronic obstructive lung disease (asthma, chronic bronchitis, and emphysema combined). We found no association between exposure to PAH or fluorides and mortality from circulatory disease.

\section{Respiratory disease}

A study conducted among aluminum plant workers in the United States showed an excess of deaths from asthma and chronic airway obstruction (3). Increased nonmalignant respiratory mortality has also been reported in a study from an eastern Canadian aluminum smelter (4), while a study from western Canada showed less evidence of increased mortality from respiratory disease (5).

Several morbidity studies have found associations between potroom work and obstructive lung disease, while some cross-sectional morbidity studies have not been able to detect any work-related respiratory effect (18). However, workers leaving or changing jobs because of symptoms would lower the prevalence of health problems in the work force and tend to attenuate dose-response associations. Cross-sectional studies may therefore have failed to detect work-related effects. Variations in the definition of occupational obstructive lung disease may also explain some of the inconsistencies between the morbidity studies (10).

The investigation of mortality from respiratory disease is problematic due to the strong mechanisms for the selection of healthy workers into the workforce, and the selection of susceptible individuals out of exposed jobs. These biases are difficult to control as they can be related to the duration of work and to exposure levels. Thus the interpretation of negative findings is difficult. The finding of weak associations should also be carefully interpreted, as the real association may be considerably stronger than suggested by the observed data. The exclusion of workers with less than 3 years of employment from our study probably reduced some of this bias. The inclusion of short-term workers may have distorted the dose-response associations due to a possible selection out of jobs and due to a higher mortality among short-term workers, probably caused by life-style factors (2). However, additional bias may still have been present as longterm workers thus formed a selected population in comparison with the general population, and also in 
comparison with workers who may have quit or changed jobs early in their career due to respiratory symptoms.

The possibility that the underlying cause of death may have been a poor measure of chronic obstructive mortality might also introduce bias (19). We therefore performed the additional analysis including the contributing causes of death from chronic obstructive lung disease in an internal analysis (table 3). The analysis showed, however, similar results as the primary analysis, and, therefore, the potential bias from the use of underlying cause of death was only judged as small by us.

A potential awareness among local physicians of an association between potroom work and respiratory disease may have led to a positive diagnostic bias. One would, however, expect reporting to be independent of exposure status, and subsequently a misclassification bias would most probably attenuate a real dose-response relation.

Three of the 7 deaths from pneumoconiosis appeared among workers employed in the Eydehavn plant. These workers had been employed for more than 20 years in a neighboring smelter producing silicon carbide (with a recognized silicosis hazard) (20). The remaining 4 deaths from pneumconioses gave thus less evidence of an association between aluminum production and pneumconioses.

\section{Circulatory disease}

It has been hypothesized that exposure to PAH may induce atherosclerosis (2) and that exposure to dust in general may increase the level of plasma fibrinogen leading to an increased risk of ischemic heart disease $(21,22)$. It has also been suggested that chronic exposure to carbon monoxide may be related to an increased risk of ischemic heart disease (23). There also exist some epidemiologic studies reporting increased risk of ischemic heart disease among workers exposed to carbon monoxide, PAH, and dust (24-26). Furthermore, a Canadian casereferent study of aluminum workers has reported increased morbidity of ischemic heart disease among potroom workers (1), but as the risk did not increase with duration of employment and did not show any association with specific agents, the Canadian study remains inconclusive. Positive associations have also been found in a small study among Norwegian aluminum smelter workers (2), but the finding was restricted to a lag time of 40 years and based on only 24 deaths from ischemic heart disease among persons exposed to coal-tar-pitch volatiles.

Neither mortality from ischemic heart disease nor mortality from cerebrovascular disease was found to be associated with agents in the work environment in the present study. However, also for circulatory disease, the selection of healthy persons into employment and sur- vival of the fittest in employment (healthy worker survival effect) may lead to bias that distorts a possible relationship. The overall evidence of an association between the work environment in the aluminum industry and circulatory mortality was considered weak.

\section{Exposure}

We had difficulties in specifically separating potential risks posed by the individual agents. The industrial hygiene measurements indicated a strong correlation between exposure to sulfur dioxide, total particulates, and fluorides. The fluoride exposure estimates should therefore be viewed as a surrogate measure also for these agents.

Despite being based on a substantial number of measurements, the estimation of exposure was inevitably subject to uncertainties, particularly in the period before 1970 , for which only few personal measurements were available. Thus misclassification of exposure was a potential threat to the study, as it may have led to the attenuation of real dose-response associations.

\section{Smoking}

Smoking is a major risk factor for the diseases of interest, but the results did not seem to have been seriously confounded by smoking. Although the smoking variable was crude, a strong association between smoking and chronic obstructive lung disease was observed, with no deaths from these diseases among the never smokers. The effect estimates in the internal subanalyses were only slightly affected after the inclusion and adjustment for smoking habits. This finding suggested that smoking was not a confounder in the present study.

\section{Residual confounding by age}

To investigate potential residual confounding due to the relative wide age intervals used, we performed some additional sensitivity analyses using 8 and 10 age groups. Since these sensitivity analyses only indicated minor changes in the effect estimates, substantial residual confounding from age seemed unlikely.

\section{Geographic variations in mortality}

The 6 aluminum plants included in our study were all located close to the coastline, but in different parts of Norway, ranging from the north to the south. As mortality varies in different parts of Norway, our use of national rates may have biased the overall SMR. If we had used local rates, the SMR would probably have become slightly higher, since the local rates in 2 of the counties were lower than the national rates for total, circulatory, and respiratory mortality. However, the comparison of industrial populations in small industrial communities with unstable local rates dominated by surrounding farming communities is probably just as questionable as the use 
of national rates. The potential bias introduced by using national rates probably did not affect the dose-response analyses since additional internal analyses including indicator variables for plant did not lead to essential changes in the effect estimates.

\section{Concluding remarks}

The study showed increased mortality from obstructive lung disease (asthma, emphysema and chronic bronchitis) among fluoride-exposed workers in the Norwegian aluminum industry. As exposure to fluoride was correlated with exposure to sulfur dioxide and total particulates, the etiologic agents remain uncertain.

No association was observed between exposure to PAH or fluorides in the work environment of aluminum smelters and circulatory mortality.

\section{Acknowledgments}

This work was part of a project supported by grants from The Nordic Aluminum Industry's Secretariat for Health, Environment and Safety and the Work Environment Fund of the Confederation of Norwegian Business and Industry.

We acknowledge support from project committee members Erle Grieg Astrup, Arvid Bastiansen, Bjørn Hilt, Sverre Langård, Eirik Nordheim, Odd Arnold Hauge, and Per Iver Øksne. We thank Jan Ivar Martinsen for his valuable help with the programming and data analyses. Alf Rønneberg started, planned, and participated in the early phases of this project. He died in 1997.

\section{References}

1. Thériault GP, Tremblay CG, Armstrong BG. Risk of ischemic heart disease among primary aluminum production workers. Am J Ind Med 1988;13:659-66.

2. Rønneberg A. Mortality and cancer morbidity in workers from an aluminum smelter with prebaked carbon anodes part III: mortality from circulatory and respiratory diseases. Occup Environ Med 1995;52:255-61.

3. Rockette HE, Arena VC. Mortality studies of aluminum reduction plant workers: potroom and carbon department. J Occup Med 1983;25:549-57.

4. Gibbs GW. Mortality of aluminum reduction plant workers, 1950 through 1977. J Occup Med 1985;27:761-70.

5. Spinelli JJ, Band PR, Svirchev L, Gallagher RP. Mortality and cancer incidence in aluminum reduction plant workers. J Occup Med 1991;33:1150-5.

6. Romundstad PR, Haldorsen T, Andersen A. Cancer incidence and cause specific mortality among workers in two Norwegian aluminum plants. Am J Ind Med 2000;37:175-83.

7. Milham S. Mortality in aluminum reduction plant workers. J Occup Med 1979;21:475-80.

8. Mur JM, Moulin JJ, Meyer-Bisch C, Massin N, Coulon JP, Loulergue J. Mortality of aluminum reduction plant workers in France. Int J Epidemiol 1987;16:257-64.

9. Kongerud J, Samuelsen SO. A longitudinal study of respiratory symptons in aluminum potroom workers. Am Rev Respir Dis 1991;144:10-6.

10. Kongerud J, Bøe J, Søyseth V. Aluminium potroom asthma: the Norwegian experience. Eur Respir J 1994;7(1):165-72.

11. Frostad EW. Fluorforgiftning hosnorske aluminiumsfabrikkarbeidere [Fluorine intoxication in Norwegian aluminium plant workers]. Tidsskr Nor Laegeforen 1936;56:179-82.

12. Midttun O. Broncial asthma in the aluminium industry. Acta Allergol 1960;15:208-21.

13. Romundstad PR, Haldorsen T, Andersen A. Cancer incidence among Norwegian aluminum workers and quantitative exposures to PAH and fluorides. Scand J Work Environ Health $2000 ; 26: 459-67$

14. Rothman KJ. Induction and latent periods. Am J Epidemiol 1981;114:253-9.

15. Checkoway H, Pearce N, Hickey JLS, Dement JM. Latency analysis in occupational epidemiology. Arch Environ Health 1990;45:95-100.

16. Breslow NE, Day NE. Statistical methods in cancer research; vol II (The design and analysis of cohort studies). Lyon: International Agency for Research on Cancer (IARC), 1987 96-7. IARC scientific publications, no 82.

17. Preston DL, Lubin JH, Pierce DA, McConney ME: Epicure. Seattle (WA): Hirosoft International Corporation, 1993.

18. Abramson MJ, Wlodarczyk JH, Saunders NA, Hensley MJ. Does aluminum smelting cause lung disease? Am Rev Respir Dis $1989 ; 139: 1042-57$.

19. Camilli AE, Robbins DR, Lebowitz MD. Death certificate reporting of confirmed airways obstructive disease. Am J Epidemiol 1991;133:795-800.

20. Brusgaard A. Pneumconiosis in silicon carbide workers. Proceedings of the 9 th International Congress on Industrial Medicine. London: Wright Briston, 1948:676-81.

21. Seaton A, Macknee W, Donaldson K, Godden D. Particulate air pollution and acute health effects. Lancet 1995;345:176-8.

22. Sjøgren B. Occupational exposure to dust: inflamation and ischaemic heart disease. Occup Environ Med 1997;54:466-9.

23. Kristensen TS. Cardiovascular diseases and the work environment: a critical review of the epidemiologic literature on nonchemical factors. Scand J Work Environ Health 1989. 15:165-79.

24. Stern FB, Halperin WE, Hornung RW, Ringenburg VL, McCammon CS. Heart disease mortality among bridge and tunnel officers exposed to carbon monoxide. Am J Epidemiol 1988;128:1276-88.

25. Maclaren WM, Hurley JF. Mortality of tar distillation workers. Scand J Work Environ Health 1987;13:404-11.

26. Evanoff BA, Gustavsson P, Hogstedt C. Mortality and incidence of cancer in a cohort of Swedish chimney sweeps: an extended follow up study. Br J Ind Med 1993;50:450-9.

Received for publication: 23 March 2000 